(REVIEW ARTICLE)

\title{
Role of hydroxychloroquine and chloroquine in prophylaxis against COVID19 review study
}

Kumar Surendra *, Gupta Harsh, Bhandiwad Chandrashekhar, Meena Babu Lal, Mali Manoj, Jangid Ravindra and K R Anil

Resident, Medicine Department, S P Medical College, Bikaner, Rajsthan, India.

Publication history: Received on 07 May 2020; revised on 17 May 2020; accepted on 21 May 2020

Article DOI: https://doi.org/10.30574/wjarr.2020.6.2.0148

\begin{abstract}
The ongoing coronavirus pandemic has pushed that global healthcare system in crises and led to huge losses in terms of life and property. Different drugs for prophylaxis against COVID-19 including Chloroquine (CQ) or Hydroxychloroquine (HCQ) have been tried. This study was performed to systematically review the role of CQ and HCQ in the prophylaxis of COVID-19. Various databases like PubMed, EMBASE, ClinicalTrials.gov, International Clinical Trials Registry Platform and Cochrane Library databases were searched for studies that evaluated the prophylactic role of CQ or HCQ on SARS-CoV-2 (pre-clinical studies) or COVID-19 (clinical studies) until 6th May 2020. The available literature was critically appraised. A total of 36 articles were screened and 4 in vitro pre-clinical studies and 2 clinical opines, 4 clinical studies and promising clinical trials registered at clinicaltrials.gov were included in analysis. The pre-clinical studies showed the prophylactic effects of CQ and HCQ against SARS-CoV-2. On the other hand, the clinical opinions advocated the prophylactic use of CQ and HCQ against COVID-19. However, no original clinical studies on the prophylactic role of CQ or HCQ on COVID-19 were available. Although Preclinical trials and in vitro studies support the use of CQ and HCQ in prophylaxis against COVID19, there is a dearth of concrete clinical data to support the same. However, in a resource poor country the benefits of chemoprophylaxis will augment the safety of Frontline workers against COVID19. Long term follow up studies and high quality randomised controlled studies are required to establish the fact more prudently.
\end{abstract}

Keywords: COVID-19; Hydroxychloroquine; Prophylaxis; SARS-CoV-2

\section{Introduction}

By the end of December 2019 a number of mysterious new cases of pneumonitis started appearing in Wuhan province which was unlike any other infection known to Health authorities. On subsequent evaluation it was found to be a Corona virus [1].' Corona viruses belong to the Corona viridae family in the Nidovirales order. Corona represents crown-like spikes on the outer surface of the virus; thus, it was named as a corona virus [2].' The 2019-nCoV share close similarity to bat corona viruses giving rise to the possibility that the disease started due to transmission from bats, though the investigation is still going on. It started in the Hubei province of Wuhan city in the Huanan Seafood market and within 1 week it infected thousands of people leaving many dead, forcing authorities to place the nearby area under quarantine [3].' On 30 January 2020, World Health Organization (WHO) officially declared the COVID-19 epidemic as a public health emergency of international concern. The emergence of SARS-CoV-2, since the severe acute respiratory syndrome corona virus (SARS-CoV) in 2002 and Middle East respiratory syndrome corona virus (MERS-CoV) in 2012 marked the third introduction of a highly pathogenic and large-scale epidemic corona virus into the human population in the twenty-first century. As of 6th May 3,588,773 cases have been recognized worldwide in 210 countries with more than 247,503 deaths and going [4].' The first case of COVID19 was detected in India on 30th January and till 6th May India amounts for 35,902 confirmed cases with 1,783 deaths [5].' This could be an underestimate due to the lower number of diagnostic tests and case identification partly due to poor health services in most countries. The mortality rate stands at $0.5-4.4 \%$.

\footnotetext{
${ }^{*}$ Corresponding author: Kumar Surendra
} 
However, this could be an overestimate as the exact denominator of the actual number of cases is underreported. A lot of research has been undertaken to develop a vaccine, but with little chance of success in the foreseeable future. A lot of medicines are under research like Ribavarine, Lopinavir, Ritonavir, Antimalarials (Chloroquine and Hydroxychloroquine) and Interferones (INF). Of these drugs the particular interest is on Chloroquine and Hydroxychloroquine. The antiviral activity of chloroquine has been studied extensively in both in-vitro and in-vivo models and it is found that chloroquine as well as hydroxychloroquine is effective for both prophylaxis as well as treatment of COVID19 infection. A 2005 study done by Martin J Vincent et al first raised the possibility that chloroquine and its derivative hydroxychloroquine might be effective at treating Coronavirus infection [6].' Chloroquine interferes with the virus's ability to replicate in two ways. First, the drug enters compartments called endosomes within the cell membrane. Endosomes tend to be slightly acidic, but the chemical structure of the drug boosts their $\mathrm{pH}$, making the compartments more basic. Many viruses, including SARS-CoV, acidify endosomes in order to breach the cell membrane, release their genetic material and begin replication; chloroquine blocks this critical step [7]. The drug also prevents SARS-CoV from plugging into a receptor called angiotensin-converting enzyme 2, or ACE2, on primate cells. When the virus inserts its spike protein into the ACE2 receptor, it sets off a chemical process that alters the structure of the receptor and allows the virus to infect [7].' An adequate dose of chloroquine appears to undermine this process, and in turn, viral replication in general.

The objective of present work was to study the role and effectiveness of Hydoxychloroquine or Chloroquine for prophylaxis against COVID19 infection.

\section{Material and methods}

We aimed to include all completed and published pre-clinical as well as clinical studies, without limitations, which evaluated the prophylactic role of CQ or HCQ on SARS-CoV-2 (pre-clinical studies) or COVID-19 (clinical studies). We also looked for commentaries, re-views, viewpoints, or opinions if original clinical studies were not available. PubMed, EM-BASE, ClinicalTrials.gov, WHO International Clinical Trials Registry Platform, and Cochrane Library (Cochrane Database of Systematic Reviews, Cochrane Central Register of Controlled Trials [CENTRAL], and Cochrane Methodology Register) were searched from inception until 27th April 2020. The search terms used in various combinations were: "chlo-roquine", "hydroxychloroquine", "anthraquinone", "CQ","HCQ", "corona virus", "corona virus disease”, "corona virus disease-19",“COVID-19", "severe acute respiratory syndrome”, "SARS-CoV-2", "prophylaxis", and "preventive”. These search terms were adapted for use with different bibliographic databases in combination with database-specific filters for stud-ies, if available.

\section{Results}

A total of 36 articles were screened and 4 in vitro pre-clinical studies and 2 clinical opines, 4 clinical studies and promising clinical trials registered at clinicaltrials.gov were included in the analysis. No original clinical study on the prophylactic role of CQ and HCQ on COVID-19 were available.

\subsection{In vitro Studies}

After the SARS epidemic in 2003 numerous scientific trails were carried to find a cure or prophylaxis against the Corona viruses. The earliest and most promising result came from a research done by Vincent MJ et al (2005) to study the use of chloroquine as potent inhibitor of Coronavirus infection and spread and found that chloroquine significantly inhibited the growth of viruses in cell lines in both Pre-infection and Post-infection models[6].' While Yao et al showed that HCQ exhibited a better in vitro anti-SARS-CoV-2 activity than CQ in Vero cells derived from the African green monkey kidney [8],' Liu et al exhibited a higher potency of CQ over HCQ in the same cell line[9].' Xiao et al enumerated that CQ and remdesivir (which inhibits RNA polymerase), as compared to five other drugs, had a better in vitro po-tency in inhibiting SARS-CoV-2 in Vero cell lines [10].' Zhou et al[11] and Colson et al[12] gave their clinical opinions advocating the possible prophylactic use of CQ and HCQ against COVID-19.'

\subsection{In vivo studies}

A study in France by Raoult et al [13] evaluated the efficacy of hydroxychloroquine in 26 patients with COVID-19 and found that administration of hydroxychloroquine $200 \mathrm{mg}$, three times a day led to a significant reduction in viral carriage on day 6 post-treatment compared to that in the control group, which did not receive hydroxychloroquine.' That study also re-vealed that adding azithromycin to hydroxychloroquine appears to more efficiently clear the virus. A subsequent study by Raoult et al. [14] involving 80 patients with COVID-19 found that treatment with hydroxychloroquine and azithromycin resulted in a rapid decline in the nasopharyngeal viral load, with a virus- negative 
rate of $83 \%$ on day 7 and a rate of $93 \%$ on day 8.' Although a control group was not included in that study, its results suggest the poten-tial of hydroxychloroquine to treat COVID-19 given that the recorded median duration of viral shedding is 20 days in survivors.

In addition to the studies cited above, a Chinese team recently released the results of a clini-cal study on hydroxychloroquine to treat COVID-19 [15].' That study divided 62 patients into a hydroxychloroquine group and a control group at a ratio of 1:1. Patients in the control group received standard treatment including oxygen therapy, antivirals, antibacterials, and immunoglobulin with or without corticosteroids. Patients in the hydroxychloroquine group received hydroxychloroquine sulfate $200 \mathrm{mg}$, twice a day for 5 days in addition to the stand-ard treatment. Results indicated that hydroxychloroquine helped reduce the time until body temperature returned to normal, it decreased the duration of cough, and it improved lung im-aging findings [15].' The above studies together favor the usefulness of hydroxychloroquine in treating COVID-19.

Chen et al, Shanghai China conducted a randomised controlled trial to test the effectiveness of HCQ in 30 adult patients who tested positive for COVID-19 [16].' Patients in the treat-ment group received 400mg HCQ for 5 days, while the control group received usual care. The result of a nasopharyngeal swab on Day 7 was used as the primary outcome. The authors report three adverse events in the control group (one patient with abnormal liver function and anaemia, and one patient with abnormal renal function), and four adverse events in the treat-ment group (two patients with diarrhoea, one with lethargy, and one patient with abnormal liver function tests), which they argue were not linked to treatment with HCQ [16].' One pa-tient in the treatment group deteriorated significantly and thus HCQ was stopped on Day 4 of the treatment. The intention-to-treat analysis revealed that the treatment group did not differ from the control group in the number of patients testing negative for COVID-19 on Day 7 (13 versus 14 patients), nor the duration of illness (all P>0.05) [16].'

\subsection{Clinical Trails}

Currently, around 142 trials that have been registered in various national and international databases involving chloroquine and hydroxychloroquine, alone or in combination with other drugs in the prevention or treatment of COVID-19. Most of them are non-blinded trials. The most promising clinical trials are mentioned in the table-1.

Table 1 The most promising clinical trials

\begin{tabular}{|c|c|c|c|c|c|c|}
\hline $\begin{array}{l}\text { NCT043086 } \\
68 \text { (USA }\end{array}$ & Recruiting & $\begin{array}{l}\text { Multi-center } \\
\text { randomized } \\
\text { parallel group } \\
\text { trial }\end{array}$ & $\begin{array}{l}1500 \text { participants } \\
\text { (Heathcare workers } \\
\text { and contacts) }\end{array}$ & HCQ & Placebo & $\begin{array}{l}\text { Incidence and } \\
\text { severity of COVID-19 }\end{array}$ \\
\hline $\begin{array}{l}\text { NCT043040 } \\
53 \text { (Spain) }\end{array}$ & Recruiting & $\begin{array}{l}\text { Multi-center } \\
\text { cluster } \\
\text { randomized } \\
\text { trial }\end{array}$ & $\begin{array}{l}3040 \text { participants } \\
\text { (COVID19 contacts) }\end{array}$ & $\begin{array}{l}\text { Antiviral } \\
\text { treatment } \\
\text { and } \\
\text { prophylaxis } \\
\text { with HCQ }\end{array}$ & $\begin{array}{l}\text { Standard } \\
\text { public } \\
\text { heath } \\
\text { measures }\end{array}$ & $\begin{array}{l}\text { Incidence } r \\
\text { secondary COVID-19 } \\
\text { cases }\end{array}$ \\
\hline $\begin{array}{l}\text { NCT043035 } \\
07 \text { (Europe } \\
\text { \& Asia) }\end{array}$ & $\begin{array}{l}\text { Not yet } \\
\text { recruiting }\end{array}$ & $\begin{array}{l}\text { Multi-center } \\
\text { randomized } \\
\text { parallel group } \\
\text { trial }\end{array}$ & $\begin{array}{l}40000 \text { participants } \\
\text { (COVID19 contacts) }\end{array}$ & CQ or HCQ & Placebo & $\begin{array}{l}\text { Number of } \\
\text { symptomatic COVID- } \\
19 \text { infections }\end{array}$ \\
\hline $\begin{array}{l}\text { NCT043184 } \\
44 \text { (USA) }\end{array}$ & $\begin{array}{l}\text { Not yet } \\
\text { recruiting }\end{array}$ & $\begin{array}{l}\text { Community- } \\
\text { Based } \\
\text { Randomized } \\
\text { Clinical Trial }\end{array}$ & $\begin{array}{l}1600 \\
\text { participants(COVID } \\
19 \text { contacts) }\end{array}$ & HCQ & Placebo & $\begin{array}{lr}\text { Number } & \text { of } \\
\text { participants } & \text { with } \\
\text { symptomatic, lab- } & \text { lanfirmed COVID-19 }\end{array}$ \\
\hline $\begin{array}{l}\text { NCT043180 } \\
15 \text { (Mexico) }\end{array}$ & $\begin{array}{l}\text { Not yet } \\
\text { recruiting }\end{array}$ & $\begin{array}{l}\text { Parallel group } \\
\text { RCT }\end{array}$ & $\begin{array}{l}400 \text { participants } \\
\text { (heathcare } \\
\text { contact workers } \\
\text { COVID19) }\end{array}$ & HCQ & Placebo & $\begin{array}{l}\text { Symptomatic COVID- } \\
19\end{array}$ \\
\hline
\end{tabular}




\section{Limitations of the current empirical data}

The in vivo studies reported have methodological deficiencies. The trials by Chen et al and Gautret and colleagues were both underpowered according to their own calculations, which may have led to an exaggeration of effect sizes and false positive results. Moreover, whilst viral status at Day 6/Day 7 were the primary outcomes, no medium- or long-term follow-up data were presented in either study. Gautret and colleagues reported that one patient tested negative for the virus on Day 6, but subsequently tested positive on Day 8. This highlights the need for long-term follow-up data. Chen et al reported that most patients included in their trial (both control and treatment group) recovered quickly from COVID-19, indicating that the researchers had recruited a sample with mild symptoms. The authors argue that the lack of severe cases may have caused a ceiling effect, which may explain the non-significant results. Gautret et al did not perform intention-to-treat analysis, excluding six patients from their analyses who had dropped out at follow-up, which may have introduced bias. Finally, Gautret and colleagues did not randomise patients to the control and treatment group, poten-tially introducing allocation bias.

\section{Discussion}

The first in vitro study pointing toward the role of CQ and HCQ as pre-exposure prophylaxis against COVID-19 was published as a research letter by Yao et al. Vero cell lines derived from African green monkey kidney were treated with CQ or HCQ before exposing to a clini-cally isolated novel corona virus strain (C-Tan-nCoV Wuhan strain 01) at a multiplicity of infection (MOI) of 0.05 . HCQ was more potent than CQ in achieving the $50 \%$ maximal ef-fective concentration (EC50) (6.25 and $5.85 \mu \mathrm{mol} / \mathrm{L}$ at 24 and 48 hours, respectively) [17].' The concentration to achieve EC50 was $>100$ and $18.01 \mu \mathrm{mol} / \mathrm{L}$ for CQ, suggesting a higher loading dose. This study led to the enthusiasm of registration of clinical trials on the prophy-lactic role CQ and HCQ. The study also highlighted the use of a high loading dose of CQ followed by a low maintenance dose to support its pharmacokinetic property of higher cellular accumulation and prolonged elimination half-life [17].' Another in vitro study by a different group of researchers from China compared HCQ to CQ at 4 different MOI. The results were contradictory to that of the previous study showing a lower EC50 of CQ than that of HCQ. Importantly the difference was even more striking at higher MOI, suggesting that in the presence of faster multiplication of the virus, CQ may perform better than HCQ. The possible reasons for the conflicting results are challenging to explain; however, it cautiously points toward extrapolation of in vitro evidence to clinical practice without robust clinical data. The French study by Gautret et al shows promising result regarding the use of HCQ along with Azithromycin for treatment of SARS-CoV2 infection while another Chinese study by Chen et al shows no significant effect of chloroquine. Hence large randomised studies are required before the prophylactic effects of HCQ and CQ can be confirmed. Nevertheless, it's a low cost option, especially given that there is dearth of PPE kits and N95 masks. Thus Chemoprophylaxis along with measures like sanitization, social distancing and Quarantine can prove to be an effective way to prevent the front line workers from contracting this infection.

Expectedly, some precautions will be needed while using both these drugs that include fre-quent monitoring of hematological parameters (RBC, WBC and platelet counts), measure-ment of serum electrolytes, blood glucose (because of hypoglycemic potential of HCQ) and hepatic as well as renal functions. Since both these drugs have the potential to prolong QTc, routine electrocardiography is essential prior to starting these drugs. Co-administration of other drugs known to prolong the QTc interval (such as anti-arrhythmic, anti-depressants, anti-psychotics, anti-histaminic, teneligliptin, ondansetron and moxifloxacin etc.) must be avoided. Moreover, addition of azithromycin to HCQ as done in French trial by Gautret et al. may increase the risk of QTc prolongation. Perform ECG daily if QTc is 450-500 msec. Ad-ditionally, hypoglycemia must be looked for in patients with diabetes, especially with concur-rent use of chloroquine/HCQ and lopinavir/ritonavir. Chloroquine and HCQ should not be used concurrently with lopinavir/ritonavir and remdisivir for anticipated QTc prolongation [18].' Finally, Pharmacovigilance on visual and mental disturbance is also closely required.

Although there are sporadic case reports of chloroquine-induced cardiomyopathy and re-versible heart failure in the literature, many studies and large meta-analysis conducted in pa-tients with rheumatoid arthritis pointed to a reduced cardiovascular risk with both these com-pounds [18].' Nevertheless, since both the drug has potential to prolog QTc, a baseline ECG should be done in patients with established cardiovascular disease.

All clinicians using these drugs must know contraindication to both these compounds; hyper-sensitivity to these agents, retinopathy, porphyria, epilepsy, pre-existing maculopathy, G6PD deficiency, recent myocardial infarction and QTc $>500$ msec [19].' 


\section{Conclusion}

The pandemic COVID-19 has pushed the world healthcare system in the abyss. It has caused a huge socio-economic burden on already strained medical system and also caused huge psy-chological impact, the effects of which will last for several years to come. Thus, there is requirement to develop an effective prophylactic drug against COVID-19 and CQ/HCQ comes with some hope. HCQ and CQ have been used for decades in patients with RA and Malaria and there is plenty of experience in dealing with both the drugs and their complications. Alt-hough evidence of chloroquine and HCQ is limited (based on the experimental data and only few small human trials), it has emerged as a cheap and scientifically proven option for prophylaxis against COVID-19 in resource constrained and COVID-19 overburdened health care system in middle and low-income countries including India where there is a severe shortage of protective gear, masks and PPE predisposing the healthcare workers to infection. Chemoprophylaxis with CQ/HCQ along with other measures like social distancing, sanitisa-tion and quarantine can prove to be an effective method to protect the workforce from con-tracting this infection. Because of the lack of robust clinical evidence to date and duly con-sidering the questionable efficacy, safety concerns, danger of deprivation of these essential drugs to legitimate patient due to panic stocking and instilling a false sense of protection among the common masses, the prophylactic use of CQ or HCQ against COVID-19 needs to be further reviewed as more data pour in.

\section{Compliance with ethical standards}

\section{Acknowledgments}

This review study was carried out at Sardar Patel Medical College and PBM Hospital, Bikaner, Rajasthan. We would like to acknowledge the support provided by the Department of Medicine for the realisation of this article.

\section{Disclosure of conflict of interest}

The authors declare there is no conflict of interest associated with this manuscript.

\section{References}

[1] Z Wu and JM McGoogan. (2020). Characteristics of and important lessons from the coronavirus disease 2019 (COVID-19) out-break in China: summary of a report of 72314 cases from the Chinese Center for Disease Control and Prevention Jama.

[2] Cascella M, Rajnik M, Cuomo A, et al. (2020). Features, Evaluation and Treatment Coronavirus (COVID-19) [Updated 2020 Apr 6]. In: StatPearls [Internet]. Treasure Island (FL): Stat Pearls Publishing.

[3] COVID 19 cases world statistics.

[4] COVID19 India statistics.

[5] Vincent MJ, Bergeron E, Benjannet S, et al. (2005). Chloroquine is a potent inhibitor of SARS coronavirus infection and spread. Virol J, 2, 69.

[6] A Savarino, JR Boelaert, A Cassone, G Majori and R Cauda. (2003). Effects of chloroquine on viral infections: an old drug against today's diseases? Lancet Infect Dis, 3, 722-727.

[7] Xueting Yao, Fei Ye, Miao Zhang, Cheng Cui, Baoying Huang, Peihua Niu, Xu Liu, Li Zhao, Erdan Dong, Chunli Song, Siyan Zhan, Roujian Lu, Haiyan Li, Wenjie Tan and Dongyang Liu. In Vitro Antiviral Activity and Projection of Optimized Dosing Design of Hydroxychlo-roquine for the Treatment of Severe Acute Respiratory Syndrome Coronavirus 2 (SARS-CoV-2), Clinical Infectious Diseases.

[8] Liu J, Cao R, Xu M, et al. (2020). Hydroxychloroquine, a less toxic derivative of chloroquine, is effective in inhibiting SARS-CoV-2 infection in vitro. Cell Discov, 6, 1-4.

[9] Wang M, Cao R, Zhang L, et al. (2020). Remdesivir and chloroquine effec-tively inhibit the recently emerged novel coronavirus (2019-nCoV) in vitro. Cell Res, 30, 269-271.

[10] Zhou D, Dai S-M and Tong Q. (2020). COVID-19: a recommendation to exam- ine the effect of hydroxychloroquine in preventing infection and progression. J Antimicrob Chemother.

[11] Colson P, Rolain J-M and Raoult D. (2020). Chloroquine for the 2019 novel coronavirus SARS-CoV-2. Int J Antimicrob Agents, 55, 105923. 
[12] Gautret P, Lagier JC, Parola P, et al. (2020). Hydroxychloroquine and azithromycin as a treat-ment of COVID-19: results of an open-label non-randomized clinical trial. Int J Antimicrob Agents.

[13] Gautret P, Lagier JC, Parola P, et al. (2020). Clinical and microbiological effect of a combi-nation of hydroxychloroquine and azithromycin in 80 COVID-19 patients with at least a six-day follow up: An observational study. Méditerranée Infection.

[14] Chen ZW, Hu JJ, Zhang ZW, Jiang S, Han SM, Yan DD, Zhuang RH, Hu B and Zhang Z. (2020). Efficacy of hydroxychloroquine in patients with COVID-19: Results of a randomized clinical trial. medRxiv.

[15] Chen J, Liu DP, Liu L, Xu QN, Xia L, Ling Y, Huang D, Song SL, Zhang DD, Qian ZP, Li T, Shen YZ and Lu HZ. (2020). A pilot study of hydroxychloroquine in treatment of patients with com-mon coronavirus disease-19 (COVID-19). Zhe Jiang Da Xue Xue Bao.

[16] Shah S, Das S, Jain A, Misra DP and Negi VS. (2020). A systematic review of the prophylactic role of chloroquine and hydroxychloroquine in coronavirus disease-19 (COVID-19). Int J Rheum Dis, 1-7.

[17] Braga CB, Martins AC, Cayotopa AD, et al. (2015). Side Effects of Chloroquine and Prima-quine and Symptom Reduction in Malaria Endemic Area (Mâncio Lima, Acre, Brazil). Inter-discip Perspect Infect Dis.

[18] Marmor MF, Kellner U, Lai TY, Melles RB and Mieler WF. (2016). American Academy of Oph-thalmology. Recommendations on Screening for Chloroquine and Hydroxychloroquine Reti-nopathy (2016 Revision) Ophthalmology, 123(6), 1386-1394.

\section{How to cite this article}

Kumar S, Gupta H, Bhandiwad C, Meena B, Mali M, Jangid R and Anil KR. (2020). Role of hydroxychloroquine and chloroquine in prophylaxis against COVID19 review study. World Journal of Advanced Research and Reviews, 6(2), 170175. 